\title{
Potent In Vitro and In Vivo Antitoxoplasma Activity of the Lipid-soluble Antifolate Trimetrexate
}

\author{
Carmen J. Allegra," Joseph A. Kovacs, ${ }^{\ddagger}$ James C. Drake, ${ }^{\star}$ Judy C. Swan, ${ }^{\ddagger}$ Bruce A. Chabner, ${ }^{\star}$ and Henry Masur \\ *Clinical Pharmacology Branch, National Cancer Institute, and ${ }^{\ddagger}$ Critical Care Medicine Department, Clinical Center, \\ National Institutes of Health, Bethesda, Maryland 20892
}

\begin{abstract}
Trimetrexate, a highly lipid-soluble quinazoline antifolate now undergoing trials as an anticancer agent, was found to be a potent inhibitor of the dihydrofolate reductase (DHFR) isolated from Toxoplasma gondii. The concentration required for $50 \%$ inhibition of protozoal DHFR was $1.4 \mathrm{nM}$. As an inhibitor of this enzyme, trimetrexate was almost $\mathbf{6 0 0}$-fold (amount of antifolate required to inhibit catalytic reaction by $50 \%$ ) and $\mathbf{7 5 0}$-fold (inhibition constant) more potent than pyrimethamine, the DHFR inhibitor currently used to treat toxoplasma infection. When the protozoan was incubated with $1 \mu M$ trimetrexate, the drug rapidly reached high intracellular concentrations. Since toxoplasma organisms lack a transmembrane transport system for physiologic folates, host toxicity can be prevented by co-administration of the reduced folate, leucovorin, without reversing the antiprotozoal effect. The effectiveness of trimetrexate against toxoplasma was demonstrated both in vitro and in vivo. Proliferation of toxoplasma in murine macrophages in vitro was completely inhibited by exposure of these cells to $10^{-7} \mathrm{M}$ trimetrexate for $18 \mathrm{~h}$. When used alone, trimetrexate was able to extend the survival of $\boldsymbol{T}$. gondii-infected mice.
\end{abstract}

\section{Introduction}

Dihydrofolate reductase (DHFR) ${ }^{1}$ (E.C. 1.5.1.3; 5,6,7,8-tetrahydrofolate: $\mathrm{NADP}^{+}$oxidoreductase) is required to maintain the intracellular pool of reduced folates in rapidly dividing cells. Inhibitors of this enzyme have proved effective in both antineoplastic and antimicrobial chemotherapy. Methotrexate potently inhibits DHFR from mammalian and bacterial sources (inhibition constant $\left[K_{\mathrm{i}}\right], 10^{-11} \mathrm{M}$ ) but requires transport by a folatespecific membrane carrier found in mammalian cells, and is therefore primarily useful as an antineoplastic agent (1). The diaminopyrimidines pyrimethamine and trimethoprim have very different properties compared with methotrexate in that they have only intermediate inhibitory activity against bacterial $\operatorname{DHFR}\left(K_{\mathrm{i}}=1 \times 10^{-8} \mathrm{M}\right)$ and even less potency against mammalian DHFR (2). Despite this reduced potency, these drugs have a major advantage over methotrexate as they readily penetrate both mammalian and bacterial cells and thus are used primarily as antibacterial agents in combination with an inhibitor of folate synthesis, such as sulfadiazine or sulfamethoxazole.

Received for publication 3 March 1986 and in revised form 12 September 1986.

1. Abbreviations used in this paper: DHFR, dihydrofolate reductase; $I_{50}$, amount of antifolate required to inhibit catalytic reaction by $50 \%$.

The Journal of Clinical Investigation, Inc.

Volume 79, February 1987, 478-482
The diaminopyrimidines, in combination with sulfonamides, have become the primary form of therapy for certain protozoal infections including toxoplasmosis (3), although little is known concerning their transport into toxoplasma trophozoites and the potency of their inhibition of protozoal DHFR.

Toxoplasma gondii infection occurs in $30-50 \%$ of North Americans, but severe or life-threatening disease occurs almost exclusively in patients with defective cell-mediated immunity who appear to reactivate previously acquired infection (3). Recently toxoplasmosis has been recognized as an unusually prevalent opportunistic infection in patients with acquired immunodeficiency syndrome (AIDS) (4).

The rapidly increasing incidence of toxoplasma encephalitis in AIDS patients has highlighted the need for more effective therapies and for alternative drugs for the considerable number of patients (up to $60 \%$ ) who develop allergic reactions or serious side effects during therapy with a sulfonamide and trimethoprim or pyrimethamine (5). No alternative regimen to sulfonamide and pyrimethamine has been found effective for the therapy of toxoplasma encephalitis. In the current study, we have found that trimetrexate (2,4-diamino-5-methyl-6-[(3,4,5-trimethoxyanilino)methyl]quinazoline), a lipid-soluble antifolate now under clinical evaluation as an anticancer drug, can be used with leucovorin as a potent and selective antiprotozoal drug with no apparent toxicity for either the mammalian host or infected cells.

\section{Methods}

T. gondii was isolated from the peritoneal exudate of BALB/c mice $3 \mathrm{~d}$ after intraperitoneal inoculation of $T$. gondii trophozoites (RH strain). The exudate was suspended in phosphate-buffered saline and the toxoplasma trophozoites were separated from inflammatory cells by differential centrifugation as previously described (6). The sedimented toxoplasma organisms were then resuspended in $1 \mathrm{ml}$ of phosphate-buffered saline containing $50 \mu \mathrm{g} / \mathrm{ml}$ of each of the protease inhibitors chymostatin and leupeptin (7). The organisms were disrupted with a 60 -s burst from a cell disrupter (Virsonic model $16-850$ ) at $4^{\circ} \mathrm{C}$. The disrupted organisms were centrifuged at $20,000 \mathrm{~g}$ for $15 \mathrm{~min}$ and the resulting supernate used as the source of DHFR. The number of organisms as well as residual contaminating peritoneal macrophages were measured by microscopic examination of all preparations before and after sonication. To determine whether the DHFR activity in suspensions of toxoplasma was influenced by contamination with adherent murine peritoneal macrophages $(<2$ cells/100 trophozoites in purified preparations), DHFR activity was assayed in peritoneal macrophage preparations from normal mice using up to $2 \mathrm{mg}$ protein/ml of assay. No discernible DHFR was detected in these preparations by either the catalytic or the methotrexate binding assays.

The catalytic activity of dihydrofolate reductase from various sources was assayed spectrophotometrically according to published methods (8). Bovine liver DHFR $(8 \mathrm{U} / \mathrm{mg})$ and rat liver DHFR $(3.7 \mathrm{U} / \mathrm{mg})$ were obtained from the Sigma Chemical Co. (St. Louis, MO); human DHFR, purified from a human breast cancer cell line (MCF-7) $(27 \mathrm{U} / \mathrm{mg})$, was a gift from Dr. Bernard Kaufman of the National Cancer Institute and 
Lactobacillus casei reductase was obtained from New England Enzyme Center (Boston, MA). In assays of DHFR activity, each cuvette contained $0.15 \mu \mathrm{mol}$ of NADPH in $160 \mathrm{mM}$ Tris- $\mathrm{HCl}, \mathrm{pH} 7.2$, and $160 \mathrm{mM} \mathrm{KCl}$ with DHFR (sample cuvette only) and various concentrations of inhibitors in a total volume of $1 \mathrm{ml}$. After a 10 -min temperature $\left(37^{\circ} \mathrm{C}\right)$ equilibration period, the reaction was initiated with the addition of 0.075 $\mu \mathrm{mol}$ of dihydrofolic acid. The reaction velocity was measured by following the change in optical density at $340 \mathrm{~nm}$. Enzyme activity was stable in the presence of the protease inhibitors leupeptin and chymostatin for at least $48 \mathrm{~h}$ at $4^{\circ} \mathrm{C}$. The specific activity of the toxoplasma DHFR in the cytosol preparation was $1.14 \pm 0.09 \mathrm{nmol} / \mathrm{min}$ per $\mathrm{mg}$ protein at $37^{\circ} \mathrm{C}\left(32 \pm 3 \times 10^{6}\right.$ trophozoites/mg protein). The catalytic activity was linear with time for $>10 \mathrm{~min}$ and with up to $1 \mathrm{mg}$ protein or $0.0012 \mathrm{U}$ of DHFR $(1 \mathrm{U}=1 \mu \mathrm{mol} / \mathrm{min})$ per assay of $1 \mathrm{ml}$ total volume. $K_{\mathrm{i}} \mathrm{S}$ were derived from conventional double-reciprocal plots of reaction velocities versus dihydrofolate concentrations over the range of 5 to $10 \mu \mathrm{M} . K_{\mathrm{i}} \mathrm{s}$ were calculated using classic competitive kinetic modeling. Differences in the rate of interation with DHFR among the various inhibitors were obviated by preincubating the enzyme with each of the inhibitors before determining the effects of the inhibitors on the reaction velocity.

The binding affinity of each of the inhibitors for the various reductases was determined relative to methotrexate by measuring the capacity of each to compete with $\left[{ }^{3} \mathrm{H}\right]$ methotrexate for binding to DHFR (9). Each $450-\mu \mathrm{l}$ assay contained $0.15 \mu \mathrm{mol}$ of NADPH, 1 pmol of $\left[{ }^{3} \mathrm{H}\right]$ methotrexate $(18 \mathrm{Ci} / \mathrm{mmol}$, sp act), and various concentrations of competitors (inhibitors) in $50 \mathrm{mM} \mathrm{KH}_{2} \mathrm{PO}_{4}, \mathrm{pH}$ 7.4. The binding reaction was initiated by the addition of $0.001-0.002 \mathrm{U}$ of DHFR. After equilibration for $10 \mathrm{~min}$ at $21^{\circ} \mathrm{C}$, adsorption of unbound labeled methotrexate was accomplished with the addition of $50 \mu \mathrm{l}$ of an albumin-coated activated-charcoal solution. Enzyme-bound $\left[{ }^{3} \mathrm{H}\right]$ methotrexate was separated from the charcoal by filtration as described by Drake et al. (10). The separated enzyme-bound $\left[{ }^{3} \mathrm{H}\right]$ methotrexate was then dissolved in $10 \mathrm{ml}$ of scintillant (Ready-Solv; Beckman Instruments, Inc., Irvine, CA) and counted in a liquid scintillation counter. The binding of methotrexate to DHFR from toxoplasma trophozoites was linear for protein concentrations up to $0.7 \mathrm{mg} / \mathrm{ml}$ in the final assay solution. All tabulated values from the binding and catalytic reactions were calculated using ALLFIT, a computer-assisted, least-squares curve-fitting program (11).

The transport of leucovorin, methotrexate, and trimetrexate was investigated using published techniques $(12,13)$. $\left[{ }^{3} \mathrm{H}\right]-l-5$-Formyl- $\mathrm{H}_{4} \mathrm{PteGlu}$ (leucovorin) was synthesized from $\left[3^{\prime}, 5^{\prime}, 7,9-{ }^{3} \mathrm{H}\right]$ folic acid by enzymatic reduction to tetrahydrofolic acid followed by formylation and purification (14). $10-20 \times 10^{6}$ freshly harvested intact toxoplasma trophozoites (RH strain) or 5-10 $\times 10^{6} \mathrm{HL}-60$ cells were suspended in $300 \mu \mathrm{l}$ of a 160 $\mathrm{mM}$ Hepes $/ 2 \mathrm{mM} \mathrm{MgCl}$ solution at $21^{\circ} \mathrm{C}$. The organisms or cells were then exposed to $1 \mu \mathrm{M}$ concentration of $\left[{ }^{3} \mathrm{H}\right]$ methotrexate $(18 \mathrm{Ci} / \mathrm{mmol}$, sp act), [ $\left.{ }^{3} \mathrm{H}\right]-l-5-$ formyl- $\mathrm{H}_{4}$ PteGlu $(1.5 \mathrm{Ci} / \mathrm{mmol}, \quad s p$ act $)$, or $\left[{ }^{14} \mathrm{C}\right]$ trimetrexate $(13.1 \mathrm{mCi} / \mathrm{mmol}$, sp act) for specific time periods followed by centrifugation at $15,000 \mathrm{~g}$ for $1 \mathrm{~min}$ through $1 \mathrm{ml}$ of F50 silicon fluid (General Electric Co., Silicone Products Div., Waterford, NY) to separate the cells from the radiolabeled media. The cell pellets were disrupted by dissolution in $0.5 \mathrm{ml}$ of $1 \mathrm{M} \mathrm{NaOH}$; the extract was dissolved in $10 \mathrm{ml}$ of scintillant and radioactivity counted in a liquid scintillation counter. Nonspecific background counts were established for each radiolabeled compound by adding the radiolabeled compound to the cells and then immediately quenching the transport of the radiolabeled compound by the addition of a 1000 -fold excess of unlabeled compound followed by processing as outlined above.

The peritoneal macrophage model (6) was used to illustrate the ability of the antifolates to inhibit toxoplasma replication in the intact cell. Peritoneal macrophages harvested from BALB/c mice were plated on Lab-Tek slides at a concentration of $10^{6} / \mathrm{ml} \mathrm{RPMI}-1640$ with $10 \%$ fetal calf serum (FCS) at $37^{\circ} \mathrm{C}$. After $24 \mathrm{~h}$, the medium was removed and 1 $\mathrm{ml}$ of toxoplasma at a concentration of $2 \times 10^{6} / \mathrm{ml}$ RPMI-1640 with $10 \%$ FCS was added to the slides; after 30 min the supernate was removed, the slides were washed vigorously, and $1 \mathrm{ml} \mathrm{RPMI-1640}$ and 10\% FCS plus drug were added. 1 and $18 \mathrm{~h}$ later the slides were stained with Diffquick (Dade Diagnostics, Aguada, PR). 200 to 400 cells were counted and the mean number of toxoplasma per vacuole was calculated. Each experiment was performed in duplicate.

In vivo animal studies were conducted using female BALB/c mice weighing $\sim 20 \mathrm{~g}$. Groups consisted of 8 to 10 animals and toxoplasmainfected animals were inoculated intraperitoneally with 50,000 T. gondii (RH strain) harvested from 3- or 4-d peritoneal exudates. All animals were given food and water ad lib. All intraperitoneal drugs were given via a 25-gauge needle, and all oral drugs were given in the drinking water. Pyrimethamine could not be solubilized for intraperitoneal injection, and a dose of $180 \mathrm{mg} / \mathrm{kg}$ per $\mathrm{d}$ represents its maximal solubility in the drinking water.

\section{Results}

To investigate the antimetabolic effects of antifolates, we examined the ability of various antifolates to inhibit DHFR from a human source, from $T$. gondii, and from a bacterial source (L. casei). For each inhibitor, the ability to inhibit the catalytic reaction was determined (Table I). Because some DHFR inhibitors such as methotrexate may be "slow" binding to DHFR as compared with the more rapid binding of the diaminopyrimi-

Table I. Comparative Inhibition of DHFR from T. gondii by Antifolates

\begin{tabular}{|c|c|c|c|c|c|c|}
\hline & \multicolumn{2}{|l|}{ Human } & \multicolumn{2}{|l|}{ L. Casei } & \multicolumn{2}{|l|}{ Toxoplasma } \\
\hline & $\begin{array}{l}\text { Inhibition of } \\
\text { enzyme activity } I_{s 0}\end{array}$ & $\begin{array}{l}\text { Relative potency } \\
\text { of binding }\end{array}$ & $\begin{array}{l}\text { Inhibition of } \\
\text { enzyme activity } I_{s 0}\end{array}$ & $\begin{array}{l}\text { Relative potency } \\
\text { of binding }\end{array}$ & $\begin{array}{l}\text { Inhibition of } \\
\text { enzyme activity } I_{s 0}\end{array}$ & $\begin{array}{l}\text { Relative potency } \\
\text { of binding }\end{array}$ \\
\hline & $\mu M$ & & $\mu M$ & & $\mu M$ & \\
\hline Trimethoprim & $1,300 \pm 250^{*}$ & 0.000033 & $0.28 \pm 0.07$ & 0.022 & $14.5 \pm 1.9$ & 0.0011 \\
\hline Pyrimethamine & $5.8 \pm 0.14$ & 0.0049 & $7.4 \pm 1.1$ & 0.00015 & $0.76 \pm 0.13$ & 0.0087 \\
\hline Trimetrexate & $0.0032 \pm 0.00064$ & 0.625 & $0.0061 \pm 0.0011$ & 0.17 & $0.0014 \pm 0.00016$ & 3.33 \\
\hline Methotrexate & $0.0012 \pm 0.00018$ & 1 & $0.0018 \pm 0.00027$ & 1 & $0.021 \pm 0.0029$ & 1 \\
\hline
\end{tabular}

The potencies of inhibition of DHFR isolated from human, L. casei, and toxoplasma for each of four antifolates-trimethoprim, pyrimethamine, trimetrexate, and methotrexate-are compared in the table. For each source of DHFR the amount of antifolate required to inhibit the catalytic reaction by $50 \%\left(I_{50}\right)$ was determined in a reaction system as described in the Methods section. Also tabulated are the relative DHFR binding potencies for each antifolate when compared with methotrexate. This value is expressed as the ratio of methotrexate concentration required to reduce $\left[{ }^{3} \mathrm{H}\right]$ methotrexate binding to DHFR by $50 \%$ in the binding assay (see Methods) as compared with the concentration of inhibitor, producing a 50\% decrease in binding, i.e., [MTX]/[inhibitor], where [MTX] or [inhibitor] equal drug concentration that reduces $\left[{ }^{3} \mathrm{H}\right]$ methotrexate binding to DHFR by $50 \%$. * SEM. 
dines (15), these experiments were conducted by preincubating each of the inhibitors for $10 \mathrm{~min}$ with enzyme before the initiation of the reaction. Methotrexate and trimetrexate were potent inhibitors of DHFR from mammalian, bacterial, or protozoal sources (amount of antifolate required to inhibit catalytic reaction by $50 \%$ [ $\left.\left.I_{50}\right], 1-21 \mathrm{nM}\right)$. In contrast, trimethoprim weakly inhibited mammalian reductase $\left(\mathrm{I}_{50}, 0.39-1.3 \mathrm{mM}\right)$ and had intermediate potency versus bacterial reductase $(0.28 \mu \mathrm{M})$, while pyrimethamine had relatively equivalent potency as an inhibitor of reductase from mammalian and bacterial sources $(6 \mu \mathrm{M})$. Both trimethoprim and pyrimethamine weakly inhibited the toxoplasma reductase with $\mathrm{I}_{50} \mathrm{~S}$ of 14.5 and $0.76 \mu \mathrm{M}$, respectively. The $\mathrm{IC}_{50}$ for inhibition of toxoplasma DHFR by trimetrexate was almost 600 -fold lower than that of pyrimethamine and 10,000-fold lower than that of trimethoprim (Fig. 1). The interaction of the various inhibitors with toxoplasma DHFR was further defined by the determination of $K_{\mathrm{i}} \mathrm{s}$. The reaction velocities in the presence of each of the inhibitors were convertible to linear double-reciprocal plots and followed a classic competitive pattern of interaction with respect to dihydrofolate. The $K_{\mathrm{i}} \mathrm{s}$ for trimetrexate, trimethoprim, and pyrimethamine were found to be $0.057 \pm 0.012,213.0 \pm 49.0$, and $43.3 \pm 10.9 \mathrm{nM}$, respectively. These values further demonstrate a marked advantage of trimetrexate when compared with pyrimethamine (757-fold) or trimethoprim (3,724-fold) as inhibitors of toxoplasma DHFR and are consistent with the relative differences in their respective $\mathrm{I}_{50}$ values. A comparison of the $K_{\mathrm{i}} \mathrm{S}$ of each inhibitor with their respective $I_{50} s$ further confirms the competitive nature of the interaction of each inhibitor with dihydrofolate (16).

As a final test of the relative potencies of these enzyme inhibitors, we compared (Table I) the binding affinities of the various antifolates to DHFR from $T$. gondii. These studies again confirm the markedly greater potency of trimetrexate and methotrexate as compared with the binding of the diaminopyrimidines. The binding studies are equilibrium studies performed in the absence of competing folate substrates, and therefore represent a measure of the relative binding affinity of each inhibitor to DHFR without a dependence on kinetic modeling and without regard for the mechanism or rate of interaction of the inhibitor with the enzyme.

We also investigated the capacity of leucovorin, methotrexate, and trimetrexate to cross the toxoplasma cell membrane, and found that classical folate structures such as methotrexate and leucovorin (Table II) did not penetrate the organisms. However, the uptake of trimetrexate was rapid, reaching a steady

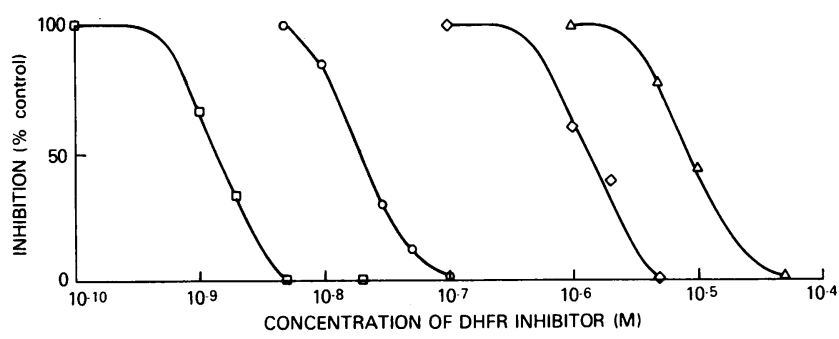

Figure 1. The percent inhibition of catalytic activity of DHFR isolated from the $T$. gondii trophozoites is illustrated as a function of the concentration of the four antifolates using the experimental conditions outlined under Table I. (Triangles) Trimethoprim, (diamonds) pyrimethamine, (circles) methotrexate, and (boxes) trimetrexate. Each point represents the mean of at least four separate experiments. The standard error is $<15 \%$, as shown in Table I.
Table II. Steady State Intracellular Concentration of Leucovorin and Antifolates in T. gondii and in Human Tumor Cells

\begin{tabular}{lclc}
\hline & Leucovorin & Trimetrexate & Methotrexate \\
\hline & pmol/10' cells & pmol/10 cells & pmol/10 $10^{7}$ cells \\
Toxoplasma trophozoites & 0 & $108 \pm 36.6$ & 0 \\
HL-60 cells & $16.0 \pm 3.5^{*}$ & $366 \pm 68.5$ & $10.3 \pm 0.5$ \\
\hline
\end{tabular}

The steady state intracellular concentrations of leucovorin and the antifolates trimetrexate and methotrexate were measured in toxoplasma trophozoites and in the human promyelocytic leukemia cell line (HL60) for comparison. The studies were performed at $21^{\circ} \mathrm{C}$ with external drug concentrations of $1 \mu \mathrm{M}$ in a $160 \mathrm{mM} \mathrm{HEPES} / 2 \mathrm{mM} \mathrm{MgCl}$ solution. Intracellular drug concentrations were allowed to reach steady state over $30 \mathrm{~min}$ and the samples processed and intracellular drug accumulation quantitated as per the Methods section.

* SEM.

state of $108 \mathrm{pmol} / 10^{7}$ cells within $10 \mathrm{~min}$. For comparison, the uptake of these compounds was quantitated in a human leukemia cell line, HL-60. All three compounds were transported by this cell line with steady state levels of methotrexate approximately equal to that of leucovorin, while trimetrexate levels were almost 30 times greater than either of the former compounds at an equivalent extracellular concentration. Accounting for the threefold difference in size between the trophozoites (32 $\times 10^{6}$ cells $/ \mathrm{mg}$ cytosolic protein $)$ and HL-60 $\left(10 \times 10^{6}\right.$ cells $/ \mathrm{mg}$ cytosolic protein), the steady state levels of trimetrexate are equivalent for the two cell types, $324 \mathrm{pmol} / \mathrm{mg}$ cytosolic protein in trophozoites and $366 \mathrm{pmol} / \mathrm{mg}$ of cytosolic protein in HL60 cells.

Studies were also performed to assess the relative potencies of the various antifolates as inhibitors of toxoplasma replication in intact toxoplasma-infected murine peritoneal macrophages, as illustrated in Fig. 2. Toxoplasma replication was $50 \%$ inhibited

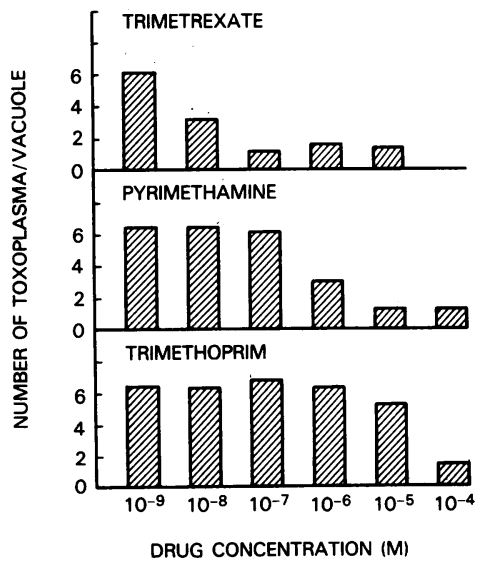

Figure 2. The inhibition of toxoplasma replication in murine macrophage monolayers is illustrated for each of three antifolates, including trimetrexate, pyrimethamine, and trimethoprim. For each experiment, macrophage monolayers were infected with the toxoplasma such that after 30 min the macrophages contained vacuoles with a single toxoplasma organism. The monolayers were then washed to rid them of free toxoplasma, drugs at the various concentrations added, and the average number of toxoplasma/vacuole measured by microscopic examination after $18 \mathrm{~h}$ of drug exposure. As per the Methods section, six toxoplasma/vacuole is equivalent to control experiments (no drug) and is indicative of no drug effect, whereas one organism/vacuole indicates total inhibition of replication by the drug at a particular concentration. Methotrexate at concentrations of up to $10^{-4} \mathrm{M}$ had no effect on replication, and the simultaneous addition of leucovorin up to $10^{-5}$ $M$ did not alter the antiprotozoal effects of the antifolates. The standard error for each experimental point was $<10 \%$. 
by a trimetrexate concentration of $10^{-8} \mathrm{M}$ and completely inhibited at concentrations in excess of $10^{-7} \mathrm{M}$. Pyrimethamine and trimethoprim required concentrations of at least $10^{-6}$ and $10^{-4} \mathrm{M}$, respectively, for equivalent activity. Methotrexate was ineffective when used at concentrations up to $10^{-4} \mathrm{M}$. In addition, concomitant addition of leucovorin (up to $10^{-5} \mathrm{M}$ ) had no inhibitory effect on the antiprotozoal effects of the drugs but prevented toxicity to the macrophages.

We performed in vivo studies to demonstrate the ability of trimetrexate to increase the survival of mice acutely infected intraperitoneally with $5 \times 10^{5}$ toxoplasma (RH strain). In preliminary studies, we found that trimetrexate, $120 \mathrm{mg} / \mathrm{kg}$ per d given intraperitoneally for $6 \mathrm{~d}$ to eight uninfected mice, was $100 \%$ lethal. The median survival of this group was $4 \mathrm{~d}$ (range 4 to $8 \mathrm{~d}$ ), and the average weight loss was $16 \%$ of the initial weight for each mouse. From day 3 until the time of death, all animals exhibited marked lethargy and hair ruffling. In contrast, simultaneous treatment with the same dose of trimetrexate and an equivalent dose of $120 \mathrm{mg} / \mathrm{kg}$ per d of $l$-leucovorin $(240 \mathrm{mg} /$ $\mathrm{kg}$ per $\mathrm{d}$ of racemic $d, \mathrm{l}$-leucovorin) for $6 \mathrm{~d}$ produced no death. The leucovorin-protected animals remained healthy appearing and active without evidence of lethargy or hair ruffling for the duration of the treatment period and for a 2-wk follow-up interval. These animals suffered a mild average weight loss of $3 \%$ of their initial weight compared with $16 \%$ for the unprotected animals at day 4 of therapy. In vivo studies were then carried out to assess the antiprotozoal effect of trimetrexate versus pyrimethamine, the drug that is conventionally used with a sulfonamide to treat toxoplasmosis in humans.

For these studies, groups of 10 mice were infected intraperitoneally with $5 \times 10^{5} T$. gondii and drug therapy was begun 24 $\mathrm{h}$ after the inoculation and continued for $14 \mathrm{~d}$. The median survival of the control group (no drug) was $7 \mathrm{~d}$, while that for the group receiving pyrimethamine $(180 \mathrm{mg} / \mathrm{kg}$ per $\mathrm{d}$ orally in the drinking water) was $8 \mathrm{~d}$. An identical dose of trimetrexate $(180 \mathrm{mg} / \mathrm{kg}$ per $\mathrm{d}$ orally in the drinking water) extended the median survival of the infected mice to $10 \mathrm{~d}$. An additional group of mice was treated with trimetrexate $(30 \mathrm{mg} / \mathrm{kg}$ per $\mathrm{d}$ i.p.) and leucovorin ( $30 \mathrm{mg} / \mathrm{kg}$ per d i.p.) and the median survival of this group was $19 \mathrm{~d}$.

\section{Discussion}

This report documents the antiprotozoal activity of trimetrexate, a lipid-soluble antifolate that is 600 -fold $\left(\mathrm{I}_{50}\right)$ and 750 -fold $\left(K_{\mathrm{i}}\right)$ more potent than the conventionally used antifolate, pyrimethamine, as an inhibitor of the protozoal DHFR. In comparative studies of inhibitors of DHFR using enzyme derived from mammalian, protozoan, and bacterial sources, the diaminopyrimidine antifolates (trimethoprim and pyrimethamine) only weakly inhibited the protozoal and mammalian enzymes, in contrast to the pteridine and quinazoline structures, which potently inhibited the enzyme from all three sources. Bacteria possess a DHFR exquisitely sensitive to the diaminopyrimidines due to the availability of additional hydrogen bonding at valine 115 as compared with the lack of bonding at this position in the insensitive mammalian enzyme (17). The combination of sulfa and a diaminopyrimidine is highly effective in treating certain bacterial infections, particularly those of the urinary tract, but the treatment of toxoplasmosis in immunosuppressed humans, particularly those with AIDS, is often unsuccessful. Many of these patients cannot tolerate such combination therapy due to allergic responses, hepatitis, or leukopenia, while other patients appear to demonstrate clinical resistance.

The inability of the toxoplasma trophozoites to transport compounds of the classic folate (pteroyl glutamate) structure precludes the effective therapeutic use of the potent DHFR inhibitor methotrexate, but offers a significant therapeutic opportunity for the combination of the lipid-soluble, readily transported antifolate trimetrexate in combination with leucovorin. The latter compound, a physiologic reduced folate (5-formyltetrahydrofolate), is taken up by host tissues and prevents the toxicity of DHFR inhibitors for bone marrow and gastrointestinal epithelium. In vitro and in vivo experiments confirm that the antiprotozoal effect of trimetrexate is preserved in the presence of leucovorin and that host toxicity of otherwise lethal doses of the drug may be averted. In the in vivo studies, trimetrexate alone was able to prolong the median survival of toxoplasmainfected mice, while pyrimethamine alone, at maximal concentrations soluble in drinking water, was found to be only minimally effective. Since the doses of trimetrexate used in this study were sublethal to allow direct comparison to equivalent pyrimethamine doses, leucovorin was not required for host protection. However, leucovorin was included in the intraperitoneal experiments to show its inability to obviate the antitoxoplasma effects of trimetrexate. Further in vivo experiments are presently being conducted to compare the efficacy of trimetrexate-leucovorin to other regimens, and these will be reported in a subsequent publication. It is likely that the addition of a sulfa to the trimetrexate-leucovorin regimen would enhance the effectiveness of this combination by inhibiting the de novo synthesis of folates in the parasite (18).

These studies suggest that lipid-soluble antifolates deserve additional scrutiny in the development of more effective and less toxic antiprotozoal therapy. Clinical trials using the combination of trimetrexate-leucovorin for the treatment of refractory toxoplasma encephalitis in the AIDS population are currently being conducted. Preliminary results suggest that the combination is an effective therapeutic option.

\section{References}

1. Chabner, B. A. 1982. Methotrexate. In Clinical Pharmacology of Antineoplastic Agents. B. A. Chabner, editor. W. B. Saunders, Philadelphia. 229-238.

2. Burchall, J. J., and G. H. Hitchings. 1965. Inhibitor binding analysis of dihydrofolate reductases from various species. Mol. Pharmacol. 1: 126-136.

3. Masur, H. 1985. Toxoplasmosis. In Cecil Textbook of Medicine. J. Wyngaarden and C. S. Smith, editors. W. B. Saunders, Philadelphia. 1792-1795.

4. Centers for Disease Control. 1986. Update: acquired immunodeficiency syndrome-United States. MMWR. 35:17-21.

5. Kovacs, J. A., J. W. Hiemenz, A. M. Macher, D. Stover, H. W. Murray, J. Shelhamer, H. C. Lane, C. Urmacher, C. Honig, D. L. Longo, M. M. Parker, C. Natanson, J. E. Parrillo, A. S. Fauci, P. A. Pizzo, and H. Masur. 1984. Pneumocystis carinii pneumonia: a comparison between patients with the acquired immunodeficiency syndrome and patients with other immunodeficiencies. Ann. Intern. Med. 100:663-671.

6. Jones, T. C., S. Yeh, and J. G. Hirsch. 1972. The interaction between toxoplasma gondii and mammalian cells. I. Mechanism of entry and intracellular fate of the organism. J. Exp. Med. 136:1157-1172.

7. McCutchan, T. F., J. A. Welsh, J. B. Dame, I. A. Quakyi, P. M. Graves, J. C. Drake, and C. J. Allegra. 1984. Mechanism of pyrimethamine resistance in recent isolates of plasmodium falliparum. Antimicrob. Agents Chemother. 26:656-659. 
8. Bertino, J., and G. Fischer. 1964. Technique for study of resistance to folic acid antagonists. Methods Med. Res. 10:297-307.

9. Myers, C. E., M. E. Lippman, H. Eliot, and B. A. Chabner. 1975. Competitive protein binding assay for methotrexate. Proc. Natl. Acad. Sci. USA. 72:3683-3686.

10. Drake, J. C., C. J. Allegra, and B. A. Chabner. 1986. A re-evaluation of the competitive protein binding assay for methotrexate binding to dihydrofolate reductase. Biochem. Pharmacol. 35:1214-1216.

11. DeLean, A., P. J. Munson, and D. Rodbard. 1978. Simultaneous analysis of families of sigmoidal curves: application to bioassay radioligand. Am. J. Physiol. 235:E97-E102.

12. Henderson, G. B., and E. M. Zevely. 1984. Transport routes utilized by L1210 cells for the influx and efflux of methotrexate. J. Biol. Chem. 259:1526-1531.

13. Kamen, B. A., E. B. Cashmore, and J. Bertino. 1984. Uptake and efficacy of trimetrexate (TMQ, 2,4-diamino-5-methyl-6-[(3,4,5-trimethoxy-anilino)methyl]quinazoline), a nonclassical antifolate in meth- otrexate-resistant leukemia cells in vitro. Biochem. Pharmacol. 33:16971701.

14. Moran, R. G., and P. D. Coleman. 1982. A simple procedure for the synthesis of high specific activity tritiated (6S)-5-formyltetrahydrofolate. Analyt. Biochem. 122:70-78.

15. Stone, S. R., and J. F. Morrison. 1986. Mechanism of inhibition of dihydrofolate reductases from bacterial and vertebrate sources by various classes of folate analogues. Biochim. Biophys. Acta. 869:275-285.

16. Cheng, Y.-C., and W. H. Prusoff. 1973. Relationship between the inhibition constant $\left(\mathrm{K}_{\mathrm{i}}\right)$ and the concentration of inhibitor which causes 50 percent inhibition $\left(I_{50}\right)$ of an enzymatic reaction. Biochem. Pharmacol. 22:3099-3108.

17. Matthews, D. A., J. T. Bolin, J. M. Burridge, D. J. Filman, K. W. Volz, and J. Kraut. 1984. Dihydrofolate reductase-the stereochemistry of inhibitor selectivity. J. Biol. Chem. 260:392-399.

18. Eyles, D. E., and N. Coleman. 1953. Synergistic effect of sulfadiazine and daraprim against experimental toxoplasmosis in the mouse. Antibiot. Chemother. 3:483-490. 